\title{
Nasarre Aznar, Sergio (2020). Los años de la crisis de la vivienda. De las hipotecas subprime a la vivienda colaborativa. Valencia: Edi- torial Tirant Lo Blanch, 656 pp.
}

Una de las principales características de la vivienda es su doble consideración de bien social y producto de mercado. Esta condición provoca que un mismo bien atienda, por un lado, necesidades humanas esenciales como el derecho a la vivienda y, por otro lado, intereses privados como la generación de riquezas para inversores financieros e inmobiliarios. Los bienes inmuebles de manera histórica han sido considerados como objetos de inversión por su alto grado de consolidación y seguridad, sin que haya podido la vivienda escapar de ello, llegando a convertirse en el único patrimonio y bien más significativo para muchas familias. Ahora bien, tanto desde la perspectiva de la economía doméstica, como de la financiera, se trata de un bien de alto costo que constituye una sustancial inversión para la que no siempre se dispone de los recursos económicos.

Un importante grupo de familias en cualquier Estado, por lo general, deben recurrir al crédito para lograr el acceso a la vivienda, fomentada con preferencia en régimen de propiedad por las políticas públicas en el ámbito mundial; o para el desarrollo de su actividad económica en el caso de los inversores. De tal manera que, la banca, a través del mercado hipotecario primario y secundario, entra en la operación económica para resolver la falta de liquidez que impide el acceso a los bienes inmuebles. No obstante, la participación de las entidades financieras en los años previos a la crisis mundial de 2007 carecía de controles normativos que regularan de manera adecuada su práctica financiera y su consiguiente refinanciación, en especial en el mercado hipotecario.

En la obra Los años de la crisis de la vivienda. De las hipotecas subprime a la vivienda colaborativa de Sergio Nasarre Aznar, catedrático de Derecho Civil y director de la cátedra Unesco de Vivienda, en seis capítulos se analizan, desde la perspectiva del derecho privado, los efectos de la consideración de la vivienda como activo financiero, se analizan desde los más detallados 
factores que contribuyeron a la generación de la crisis y burbuja inmobiliaria de 2007, hasta las estrategias jurídico-financieras más novedosas para superar sus efectos negativos. Una lectura que, además de sus aportes propios para la materia, resulta de gran utilidad en el contexto que deja para la vivienda la pandemia de la Covid-19.

En el primer capítulo consigue lograr que el lector, técnico o no, pueda comprender de manera muy clara la relación entre el mercado hipotecario y el derecho a la vivienda. En palabras del propio autor "existe una importante interrelación entre la concesión de hipotecas, el prestatario y su refinanciación” con capacidad para "crear tensión en la vivienda por su calidad de derecho humano y activo financiero". De la mencionada relación es justo de donde el autor extrae los principales factores generadores de la crisis financiera e inmobiliaria de 2007, entre los que menciona: la originación masiva de hipotecas de baja calidad o excesiva relajación (subprime), el deseo de la vivienda en propiedad respaldado por las condiciones del mercado y la falta de otras alternativas efectivas de tenencia, la débil supervisión pública de la actividad hipotecaria, así como la extensión de la refinanciación hipotecaria apoyada en la emisión de títulos valores de tipo MBS que, a su vez, se apoyaban en hipotecas subprime respaldadas, en su mayoría, por viviendas.

Los mencionados factores generadores de la crisis de 2007 podían identificarse de forma clara en las hipotecas estadounidenses de los años anteriores. 364 Por ello, en el segundo y tercer capítulo de la obra, se detiene a estudiar los productos hipotecarios estadounidenses que dieron lugar a la referida crisis, aquellos dirigidos a financiar el 100\% del valor de la vivienda como los piggy back mortgages respaldados por seguros bancarios o incluso los HELOC de tipo segunda hipoteca con los que se ofrecía hasta el 110\% del valor de la vivienda. Se estudian a fondo, además, las numerosas entidades intervinientes en la originación de los préstamos hipotecarios refiriéndose a la complejidad de su control, así como a la importancia del Registro de la Propiedad y su significado para las hipotecas que, en Estados Unidos se consideran válidas sin la constancia de su registro, pero que es este el que define el nivel jerárquico de los acreedores.

Asimismo, el autor ofrece un copioso análisis sobre la titulización hipotecaria con el que se puede comprender el mercado secundario de hipotecas estadounidenses que, a su vez, se va contrastando con el mercado español. También muestra cómo en Estados Unidos se pretendió, mediante un sistema erróneo, dinamizar el crédito territorial e inyectar liquidez al mercado hipotecario primario amparándose en hipotecas sobre viviendas cuyos deudores eran considerados débiles. Además, señala la importancia de una diáfana calificación del riesgo y como se estructuró el "preludio de la crisis de 2007".

En lo que respecta a la gestión de la crisis en España, Sergio Nasarre Aznar, en el capítulo cuarto de su obra, destaca que, lo que parecía un asunto económico y financiero pronto se convirtió en social y político provocando numerosos cambios legislativos y transcendentales pronunciamientos judiciales. 
Asimismo, señala que los cambios legislativos del periodo 2013-2017 fueron desacertados y tardíos, llegando a calificarlos como "ensayo-error" que, además, dieron paso a su denominada "robinprudencia" una práctica mediante la cual los jueces españoles se separaron del ordenamiento jurídico civil para crear una especie de legislación adyacente o complementaria basada en la equidad para proteger a "los débiles consumidores hipotecarios frente a las fuertes entidades de crédito". Una cuestión que más que alentar a los afectados provocó inseguridad jurídica en relación con el mercado hipotecario, a lo que se ha puesto fin con la entrada en vigencia de la Ley 5/2019 de 15 de marzo, reguladora de los contratos de crédito inmobiliario (Ley $5 / 2019)^{1}$, resultante de la directiva 2014/17/UE del Parlamento Europeo y del Consejo, del 4 de febrero de 2014 (directiva 2014/17/UE) ${ }^{2}$, a la que el auto le dedica una pormenorizada revisión.

Es evidente que debe distinguirse el carácter que entraña la primera vivienda y la necesidad de protegerla de las consecuencias que conlleva el considerarle sin más activo financiero y exponerle a los efectos adversos del mercado financiero. En este sentido, Sergio Nasarre expresa que "no debería estar permitido especular con primeras viviendas" lo que aplica para las distintas formas de tenencia y destaca la necesidad de considerar la vivienda como un bien especial en derecho civil como se explica en el capítulo quinto de la obra. En este sentido, destacan entre las distintas tesis que defiende el autor en su profunda investigación, respaldada con unas 1796 referencias y acompaña de numerosos gráficos y tablas comparativas, su atinado apunte al referir que: tanto en Estados Unidos como en España uno de los grandes fallos fue la concesión irresponsable del crédito hipotecario, lo que, a su vez, llevó al sobreendeudamiento de las familias, desembocando en masivas ejecuciones hipotecarias y desahucios. Un escenario que evidenció la necesidad de estructuras o fórmulas financieras sanas, así como una regulación europea para la protección del consumidor hipotecario cuyo objeto fuese el mercado residencial o una vivienda habitual.

En el último capítulo el autor destaca la importancia del ahorro previo y la necesidad de diversificar las formas de tenencia de la vivienda, así como de explorar las tenencias intermedias para ir más allá de la propiedad absoluta y el alquiler limitado. Se refiere a figuras jurídicas, relativamente novedosas, como las figuras catalanas de la propiedad compartida y la propiedad temporal, o las cooperativas de vivienda en uso, las que, incluso, pueden desarrollarse mediante estructuras de vivienda social, con las que se pueden impedir volver a los años de la crisis de la vivienda, así como romper el perpetuado binomio compra-alquiler que ofrece el mercado inmobiliario y evitar continuar construyendo una "sociedad de ricos propietarios y pobres inquilinos". Dicho todo lo anterior, y como apasionada del derecho a la vivienda y de la disciplina

\footnotetext{
${ }^{1}$ BOE, 16 de marzo de 2019, núm. 65, 26329 a 26398.

${ }^{2}$ Diario Oficial de la Unión Europea, de 4 de febrero de 2014, 60/34 a 60/85.
} 
del Housing en general, resulta una obra imprescindible para la materia, así como un valioso aporte para la comunidad jurídica, la académica y el lector en general. Un gran referente que también puede aprovechar América Latina.

\author{
SigLAS Y ABREVIATURAS \\ BOE Boletín Oficial del Estado \\ HELOC Home Equity Line of Credit. \\ MBS Mortgage-Backed Securities \\ núm. número \\ UE Unión Europea \\ Unesco Organización de las Naciones Unidas \\ para la Educación, la Ciencia y la Cul- \\ tura
}

Maridalia Rodríguez Padilla 